\title{
Simultaneous Use of Intravenous Lipid Emulsion and Plasma Exchange Therapies in Multiple Drug Toxicity
}

\author{
Mucahit Avcila Mucahit Kapçı ${ }^{a}$ Irfan Yavaşoğlu ${ }^{b}$ Burçak Kantekin ${ }^{a}$ \\ Mahmut Akpek ${ }^{\mathrm{C}}$ \\ Departments of ${ }^{\mathrm{a}}$ Emergency Medicine, ${ }^{\mathrm{b}}$ Hematology Medicine and ${ }^{\mathrm{c} C a r d i o l o g y}$, Adnan Menderes University \\ Hospital, Aydın, Turkey
}

\section{Key Words}

Lipid emulsion · Plasma exchange - Multiple drug toxicity

\begin{abstract}
Objective: The aim of this study was to highlight the use of combined intravenous lipid emulsion (ILE) and plasma exchange (PE) therapies in multidrug toxicity. Clinical Presentation and Intervention: A 45-year-old woman who attempted suicide by ingesting large quantities of amisulpride (28 g), diazepam (250 mg), valsartan (2,240 mg), aripiprazole (45 mg) and paliperidone (21 mg) was taken to the hospital of Adnan Menderes University School of Medicine. Upon arrival, she exhibited signs of cardiotoxicity and severe depression of the central nervous and respiratory systems. She was treated successfully with ILE for $4 \mathrm{~h}$ and PE therapy for $36 \mathrm{~h}$, consecutively. She was discharged on the fourth day of hospitalization having fully recovered. Conclusion: The patient was successfully treated with the combination of ILE and PE.
\end{abstract}

(c) 2016 S. Karger AG, Basel

\section{Introduction}

The management of multiple medication toxicity among patients admitted to emergency departments remains a challenge [1]. Each drug has its characteristics in effect and metabolism. Multiple treatment modalities including antidotes of medication, charcoal, lipid emulsion therapy, specific anticore to the drug and plasma exchange (PE) have been used based on the mechanism of drug intoxication. Here, we present a case of multiple medication toxicity and successful patient management.

\section{Case Report}

A 45-year-old woman who attempted suicide by ingesting large quantities of antipsychotic, benzodiazepine and antihypertensive drugs was taken to the hospital of Adnan Menderes University School of Medicine in a critical condition. Based on information from the patient's family, the ingested drugs were amisulpride (28 g), diazepam (250 $\mathrm{mg})$, valsartan (2,240 mg), aripiprazole $(45 \mathrm{mg})$ and paliperidone $(21 \mathrm{mg})$. She arrived at the emergency department in a critical condition approximately $2 \mathrm{~h}$ after the ingestion. Upon arrival, she exhibited signs of cardiotoxicity, including QT interval prolongation and atrial fibrillation (fig. 1a), in addition to profound hypotension and severe depression of the central nervous and respiratory systems. Her oxygen saturation was $79 \%$ using pulse oximetry and her pulse was 110 beats $/ \mathrm{min}$. The patient was monitored and fluid replacement was commenced. Flumazenil ( $0.1 \mathrm{mg}$ i.v.) was administered because diazepam was the likely cause of her respiratory depression. The patient became agitated and her respiratory condition deteriorated, hence she was sedated and intubated 10 min following her arrival. An infusion of dopamine and norepinephrine was started because of persistent hypotension despite the rapid infusion of normal saline. Gastric irrigation was per-

\begin{tabular}{ll}
\hline KARGER & $\begin{array}{l}\text { () 2016 S. Karger AG, Basel } \\
1011-7571 / 16 / 0256-0577 \$ 39.50 / 0 \quad \text { Karger }\end{array}$ \\
$\begin{array}{l}\text { E-Mail karger@karger.com } \\
\text { www.karger.com/mpp }\end{array}$ & $\begin{array}{l}\text { This is an Open Access article licensed under the terms of the } \\
\text { Creative Commons Attribution-NonCommercial 3.0 Un- } \\
\text { ported license (CC BY-NC) (www.karger.com/OA-license), } \\
\text { applicable to the online version of the article only. Distribu- } \\
\text { tion permitted for non-commercial purposes only. }\end{array}$
\end{tabular}

Mahmut Akpek, MD

Department of Cardiology

Adnan Menderes University Hospital

Museum Avenue, TR-09100 Aydin (Turkey)

E-Mail mahmutakpek@yahoo.com 


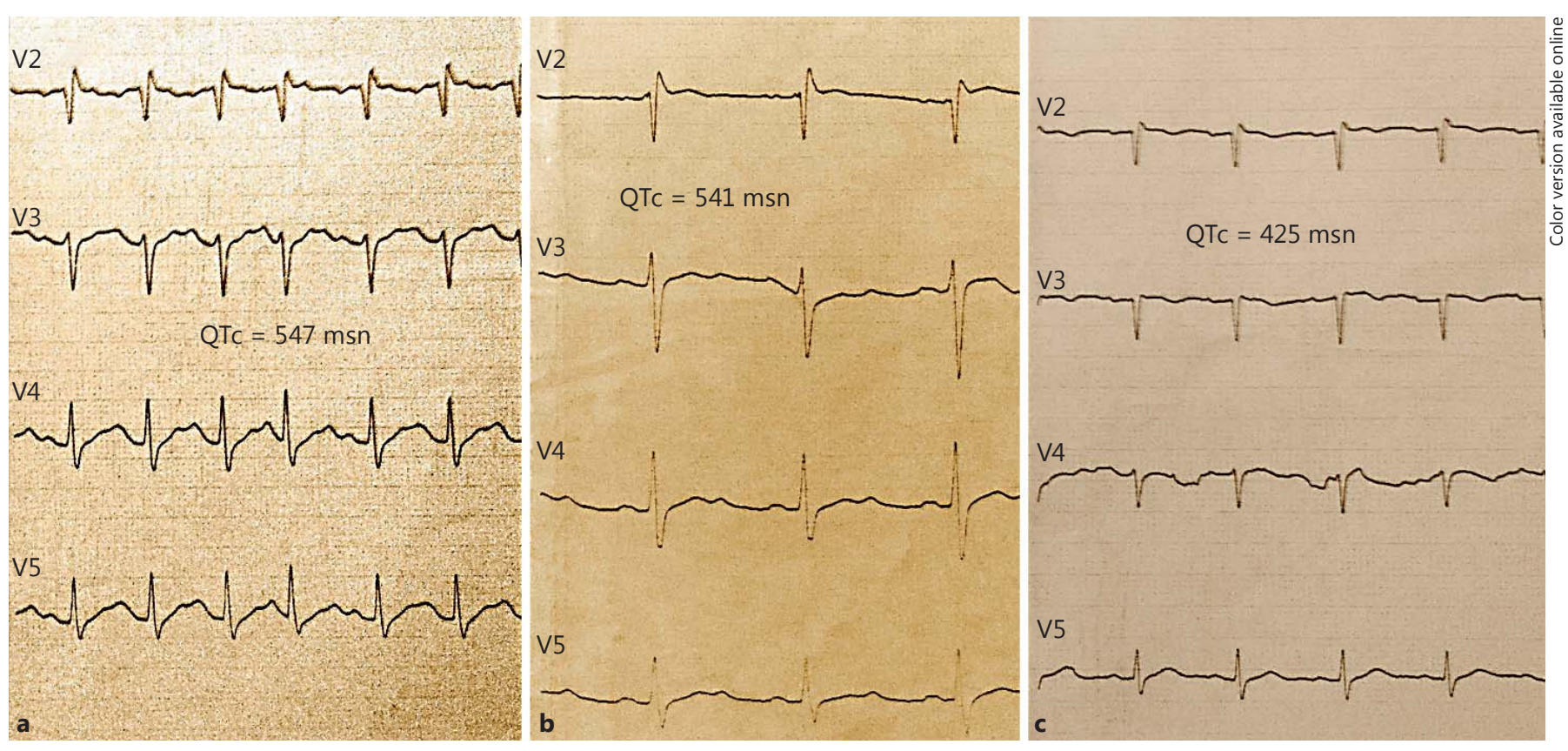

Fig. 1. Corrected QT interval on electrocardiography: on admission (a), after the ILE and PE therapy (b), and before discharge $(\mathbf{c})$.

formed and activated charcoal $(1 \mathrm{~g} / \mathrm{kg})$ was administered. The patient was then taken urgently to the emergency critical care unit. Initial laboratory data revealed a sodium level of 133 $\mathrm{mmol} / \mathrm{l}$, potassium level of $2.8 \mathrm{mmol} / \mathrm{l}$, and an arterial blood gas analysis revealed a $\mathrm{pH}$ of 7.22. Her partial pressure of carbon dioxide was $30.7 \mathrm{~mm} \mathrm{Hg}$, partial pressure of oxygen was $70.3 \mathrm{~mm}$ $\mathrm{Hg}$, bicarbonate was $12.9 \mathrm{mmol} / \mathrm{l}$ and lactate was $7.0 \mathrm{mmol} / \mathrm{l}$. All other electrolytes, creatinine, blood urea nitrogen, glucose, hepatic transaminases, troponin and coagulation study results were within normal ranges. An infusion of sodium bicarbonate $(20 \mathrm{mEq} / \mathrm{h})$ was initiated due to acidosis in the blood gas report and potassium replacement was also started. Because the patient exhibited persistent hypotension despite vasoconstrictor therapy and her metabolic condition did not improve, intravenous lipid emulsion (ILE) therapy (Smoflipid; Fresenius Kabi, Bad Homburg, Germany) was started at a rate of $100 \mathrm{ml} / \mathrm{h}$ via the central venous catheter. One hour later PE therapy (1 plasma volume) was carried out. Following this procedure, the ECG returned to sinus rhythm and the QT interval shortened to $541 \mathrm{~ms}$ (fig. 1b). The patient's blood pressure started to improve. The ILE infusion was continued $(100 \mathrm{ml} / \mathrm{h})$ for an additional $4 \mathrm{~h}$ after the PE therapy. The PE procedure was repeated 18 and $36 \mathrm{~h}$ following arrival, and the patient was extubated after $40 \mathrm{~h}$. Her general condition progressed well after extubation. The patient did not develop any additional problems and was discharged from the hospital in good condition 4 days following her admission. Her QTc was $425 \mathrm{~ms}$ on discharge (fig. 1c). During a follow-up appointment 20 days later, the patient's only complaint was mild hoarseness that was thought to be a complication of intubation.

\section{Discussion}

The present case demonstrated the successfully management of a life-threatening multiple medication toxicity using ILE and PE therapies. The patient ingested large doses of amisulpride, diazepam, valsartan, aripiprazole and paliperidone. Amisulpride is an atypical antipsychotic drug that is used for the treatment of schizophrenia. Since it is highly bound to tissues in toxic dose ingestions, hemodialysis and hemofiltration are ineffective [2]. Diazepam is metabolized in the liver and eliminated by the kidneys. It is highly bound to plasma proteins and hemodialysis offers limited benefit in the case of an overdose [3]. Valsartan is an angiotensin receptor blocker used for the treatment of hypertension. Although its toxic dose is not known, hemodialysis does not provide much benefit in the case of an overdose [4]. Aripiprazole is highly bound to plasma proteins and it is metabolized in the liver. It is also not cleared with hemodialysis [5]. Paliperidone is another antipsychotic drug used for the treatment of schizophrenia. It is bound to plasma proteins at a rate of $74 \%$ and its volume of distribution is high.

Severe intoxication caused by antipsychotic medications causes marked hypotension in addition to prolongation of the QT interval and QRS complex. It can also lead to coma, seizures and respiratory arrest [2]. Similarly, in- 
toxication due to benzodiazepines causes lethargy, speech apraxia, ataxia, coma and respiratory arrest. Unlike antipsychotic drugs, coma caused by benzodiazepines can be treated with flumazenil. In the case of intoxication due to angiotensin receptor blockers, hypotension, hyperkalemia and bradykinin-mediated effects can occur. The therapeutic dose range of amisulpride is $400-1,200 \mathrm{mg} /$ day. Our patient arrived at the hospital after ingesting $28 \mathrm{~g}$ of amisulpride. The presentation included prolongation of the QT interval, bradycardia and hypotension, giving the impression of effects of antipsychotic drugs (amisulpride, aripiprazole, paliperidone), and in particular of amisulpride. The initial ECG showed prolongation of the QTc (547 ms) without tachycardia or prolongation of the QRS complex, although the patient did have bradycardia and hypotension. The diazepam, however, could have contributed to the patient's shallow respirations and central nervous system depression. The marked hypotension may have been partly related to the valsartan. Atrial fibrillation is not specifically stated in cases of intoxication from the abovementioned drugs. However, we can speculate that atrial fibrillation was the combined effect of multiple drug toxicity and recovered spontaneously.

In the management of the present case, ILE and PE therapies were deemed appropriate, in addition to conventional treatments that included charcoal and flumazenil, due to the patient's critical condition that had a risk of rapidly progressing to death. This was supported by the exposure to toxic doses of multiple drugs with different characteristics in terms of metabolism. ILE therapy was first reported in the literature for its quick and effective management of fatal intoxications of local anesthetics [6]. The efficacy of ILE is believed to result from its capacity to bind lipid soluble agents in blood and tissues [7]. In our case, all of the medi- cations taken by our patient have lipophilic characteristics and ILE therapy continued determinedly. The patient then became hemodynamically stable. Therefore, considering the evidence in the literature, it was determined that ILE treatment would be useful and efforts should continue determinedly. In recent years, PE has been studied as a nonspecific treatment method in emergencies such as toxic ingestions [8]. In general, drugs with high lipoprotein binding rates and low volumes of distribution are effectively eliminated from the blood using PE [9]. Among the drugs taken by the patient, valsartan is the only one with high plasma protein binding and a low volume of distribution. Therefore, it is the only one that would have been eliminated with $\mathrm{PE}$. This is in contrast with the general characteristics of antipsychotics, and in particular amisulpride, which include a very low rate of binding to lipoproteins [10].

\section{Conclusion}

In this case, the patient was successfully treated with the combination of ILE and PE. The clinical condition and ECG findings of the patient improved dramatically immediately after the sequential use of ILE and PE therapies in addition to conservative therapy. Therefore, the combination of these treatment modalities has a promising future in the management of multiple drug intoxication and the treatment strategy should be individualized according to patients' clinical conditions.

\section{Disclosure Statement}

The authors have no conflicts of interest to report.

\section{References}

1 Gerace E, Petrarulo M, Bison F, et al: Toxicological findings in a fatal multidrug intoxication involving mephedrone. Forensic Sci Int 2014;243:68-73.

-2 Kotan Z, Ertepe B, Akkaya C, et al: Metabolic, endocrinologic and cardiac effects of amisulpride: a 24-week follow-up study. Ther Adv Psychopharmacol 2011;1:189-196.

-3 Agarwal SK, Kriel RL, Brundage RC, et al: A pilot study assessing the bioavailability and pharmacokinetics of diazepam after intranasal and intravenous administration in healthy volunteers. Epilepsy Res 2013;105:362-367.

-4 Forrester MB: Valsartan ingestions among adults reported to Texas poison control cen- ters, 2000 to 2005. J Med Toxicol 2007;3:157163.

5 Swainston Harrison T, Perry CM: Aripiprazole: a review of its use in schizophrenia and schizoaffective disorder. Drugs 2004;64: 1715-1736.

6 Rosenblatt MA, Abel M, Fischer GW, et al: Successful use of a $20 \%$ lipid emulsion to resuscitate a patient after a presumed bupivacaine-related cardiac arrest. Anesthesiology 2006; 105:217-218.

7 Zhou Y, Zhan C, Li Y, et al: Intravenous lipid emulsions combine extracorporeal blood purification: a novel therapeutic strategy for severe organophosphate poisoning. Med Hypotheses 2010;74:309311.

8 Karacı M, Özçetin M, Dilsiz G, et al: Severe childhood amitriptyline intoxication and plasmapheresis: a case report. Turk J Pediatr 2013;55:645-647.

-9 Ibrahim RB, Balogun RA: Medications in patients treated with therapeutic plasma exchange: prescription dosage, timing, and drug overdose. Semin Dial 2012;25:176-189.

10 Kristiana I, Sharpe LJ, Catts VS, et al: Antipsychotic drugs upregulate lipogenic gene expression by disrupting intracellular trafficking of lipoprotein-derived cholesterol. Pharmacogenomics J 2010;10:396-407. 